\title{
Effort and time in pipeline milking
}

\author{
H. W. VOS \\ Laboratory for Animal Physiology, Agricultural University, Wageningen, Netherlands
}

\section{Summary}

Heart rate, energy expenditure and time were compared in milkers using a pipeline or ordinary (standing) buckets. These milking methods were applied in a cowshed and a milking parlour to cows yielding different amounts of milk. Milking was done with two milking units. The cows were machine stripped. The measurements were made on six subjects in the cowshed and three in the milking parlour.

The total energy expenditure, which was only measured in order to get an impression of the average value, was $5.0 \mathrm{kcal} / \mathrm{min}$. The individual values varied greatly owing to the great variation in performance and the different methods used. The energy expenditure and the heart rates indicate a light to moderately heavy physical workload.

In cowshed milking no difference in physical effort could be shown between the two milking methods, probably owing to the fact that the weight carried was not large.

In parlour milking the mean heart rate seemed to be slightly higher during milking in ordinary buckets than during the pipeline milking. The heart rate remained at the same level during the emptying of the buckets and the operations immediately succeeding as the heart rate during preparation of the cows. In any case, peak loads could not be shown.

The performance with pipeline milking showed an $18 \%$ increase in the cowshed and a $9 \%$ increase in the milking parlour on milking in ordinary buckets. The performance with both methods was low because of the low milking rate assessed by Dutch standards.

The heart rate was increased very clearly during carrying of the filled milkcans. During cleaning of the utensils the effort was also greater than during milking.

Some suggestions are given in order to simplify work control. This could lead to a decrease in the mental effort needed in high milking performances.

\section{Introduction}

According to the literature on machine milking, several advantages in labour are attributed to milking directly in a pipeline as compared with milking with a bucket type of milking machine.

The advantages claimed are as follows: -

1. The work could require less effort and be simplified.

2. There could be a saving of time.

3. The quality of the work could be improved because more time is available for control.

The time-saving is calculated from time studies and could amount to 5-25\% for such different milking methods as cowshed and parlour milking, and milking by hand and machine stripping (BORN and VRIEND, 1960; PostMA and VAN EL̃dEREN, 1963).

The human workload in machine milking is not very heavy, as has been shown in

Received for publication 3rd May, 1965. 
different investigations by measuring the energy expenditure (HETTINGER and WIRTHS, 1953; ROBERTS, 1961). In other investigations it was shown that milking and stripping by hand raised the heart rate considerably (Politiek and DE RooY, 1962; STREeF, VAN LOON and VOS, 1959). A milking method with machine stripping, which eliminated the latter operation, would probably be less of a strain on the milker, and his performance will usually increase when the work is facilitated.

Since on many farms milking increases the normal daily hours of work in the morning and evening and at week-ends, it is only logical to minimize human effort during milkings. The effort expended in pipeline milking has not hitherto been investigated, and it was therefore considered advisable to study the effort and time spent in this method.

The results are given of a number of experiments in which pipeline milking was compared with milking in ordinary (standing) buckets.

\section{Experimental methods}

The experiments were carried out in an ordinary cowshed in winter, when the milk yield of the cows was low (average was $3.5 \mathrm{~kg} / \mathrm{cow}$ during afternoon milking) and in a double-row, four-stall milking parlour (chute type) in summer. Average milk yield was then $7.5 \mathrm{~kg} / \mathrm{cow}$ in the morning and $6.0 \mathrm{~kg} / \mathrm{cow}$ in the afternoon.

\subsection{Cow s hed}

In the cowshed the heart rate was measured on six milkers each milking 20 cows, once with pipeline (method M) and once with ordinary buckets (method A).

In order to eliminate sequence effects of the heart rate in succeeding tests, the cows were divided into two groups of 10 cows each. One method was applied at the beginning and end of a test range, the other method in the second and third milking period of the range. A typical test range was $\mathbf{M}_{1}-\mathbf{A}_{1}-\mathbf{A}_{2}-\mathbf{M}_{2}$, in which the index number represents the first or second group of 10 cows. The range of tests was performed in four succeeding days with each subject.

In both methods two milking units were used. The cows were washed and prepared by hand; before the teat-cups were removed the udder was stripped (machine stripping). With pipeline milking the milk flowed to 30 -litre milk cans in the dairy room. The pipeline and teat-cups were cleaned automatically. The lids and connection pipes and other milk utensils were cleaned by hand.

When ordinary buckets were used the milk was carried to milk cans outside the cowshed at an average distance of 6 metres from the cows. After milking the milk cans were carried 12 metres to the dairy room. The units, buckets and other utensils were cleaned by hand.

\subsection{Milking parlour}

The milking parlour was a movable two-level one standing in the pasture on which the cows grazed (FIG. 1).

The test series were arranged differently from those in the cowshed. In the milking parlour the heart rate was measured on three subjects during morning and afternoon milking. Each test was duplicated. The 21 cows were divided into two groups of 10 and 11 cows. A typical test range during the four morning milkings was $A_{1} M_{2}-$ $M_{1} A_{2}-A_{1} M_{2}-M_{1} A_{2}$. After milking the 10th cow of the 1st group the methods were reversed. The tests were carried out in four succeeding days for each milker. 
FIG. 1. The movable milking parlour on a concrete floor (four stalls, chute type)

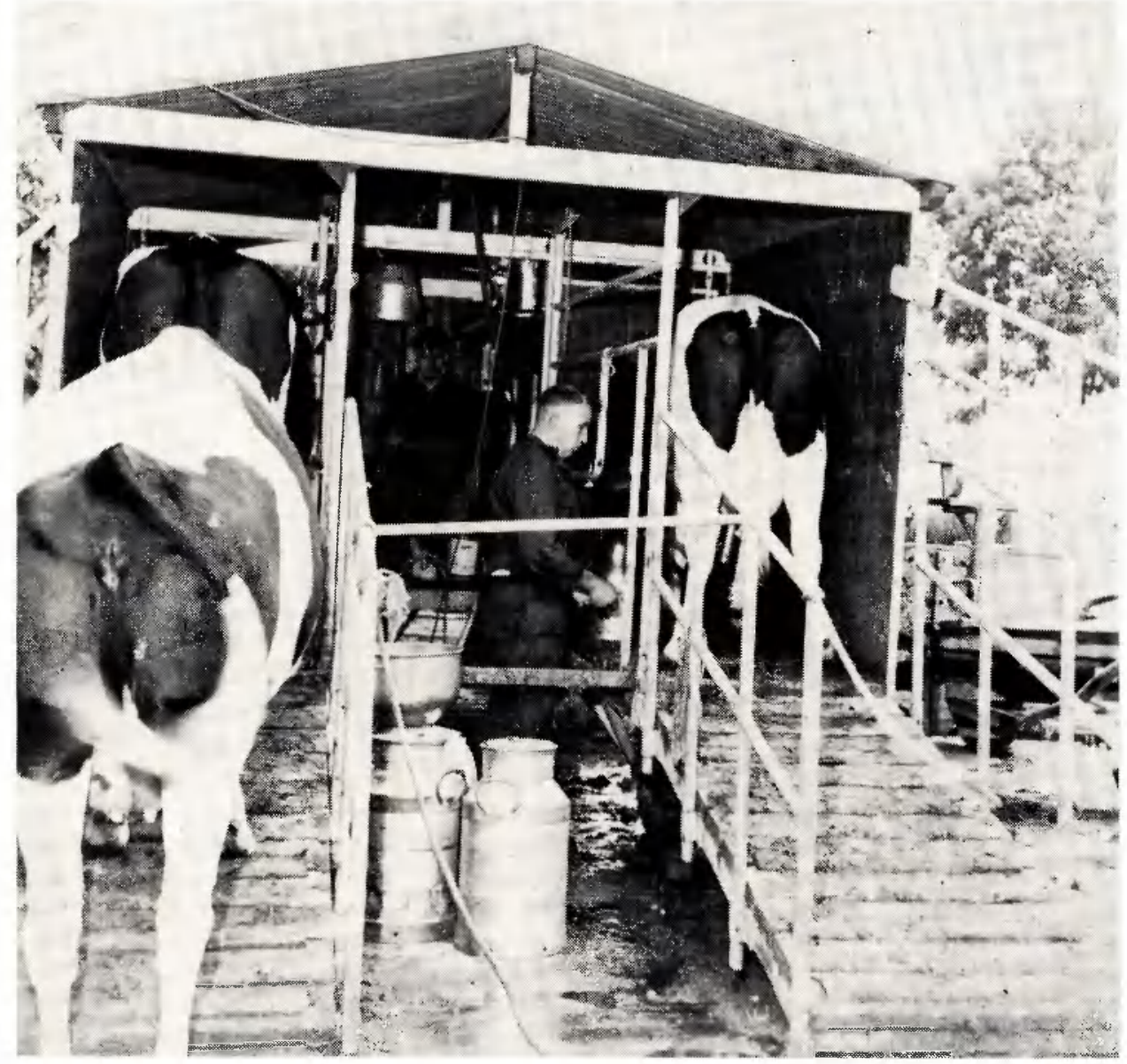

With pipeline milking a 150-litre container was used, placed on a waggon alongside of the parlour. The pipeline and the teat-cups were cleaned automatically.

The buckets were emptied in 30-litre cans placed in the parlour before milking started, and carried out and lifted on the waggon after milking. The buckets and milking utensils were cleaned by hand.

\section{3. $\quad \mathrm{M}$ e a s u r e me n t s}

The heart rate was recorded continuously during milking, transport of the cans and cleaning of the buckets and other utensils. For the recording the electrocardiographic method was used. The time spent on each operation was recorded. In addition, in order to get an impression of the average value, the energy expenditure of each subject was measured once during cowshed milking. This was done with a portable Müller and Franz dry gasometer (Müller and Franz, 1952). The oxygen content 
was analysed with a Haldane apparatus, the energy expenditure being calculated according to WEIR (1949).

The subjects were normally skilled milkers, who with the exception of subject EV milked these cows regularly. Their ages varied from 23 to 51 years.

\section{Results}

The energy expenditure was measured in a period of $7 \mathrm{~min}$. During this time two or three cows were milked. The average total energy expenditure of the six milkers, of whom three milked with pipeline and the others with buckets, was $5.0 \mathrm{kcal} / \mathrm{min}$ (range $3.6-6.2 \mathrm{kcal} / \mathrm{min}$ ).

The great variation in energy expenditure is to be connected with the different performances of the subjects and the different work methods during the measurements. According to ChrIsTENSEN's (1953) classification, machine milking as employed in these experiments could be considered as light to moderately heavy work.

The mean heart rate and the mean performance of each subject during cowshed milking (in the afternoon) and parlour milking (in the morning and afternoon) is shown in TABLE 1.

TABLE 1. Effort and performance in machine milking with pipeline (M) and regular buckets (A)

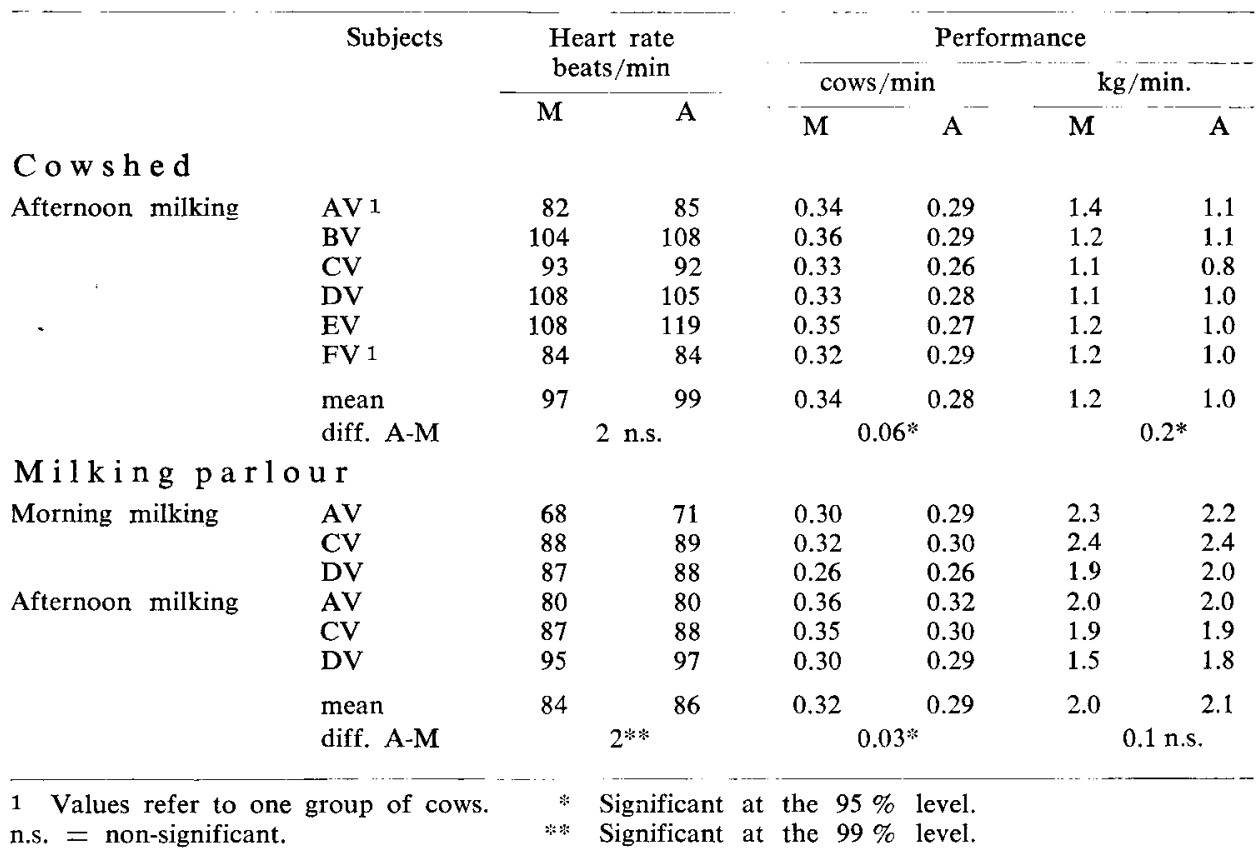

In the cowshed the mean heart rates and performances were calculated over the period from the preparation of the first cow to the removal of the teat-cups, or the emptying of the buckets of the last cow. The same method of calculation could not 
be used in the milking-parlour tests because methods $M$ and $A$ had to be changed at the 9 th and 10th cow of the first group and the normal milking routine could not be continued. The mean heart rate was now calculated over a period in which at least 8 cows were milked. The milking performance was calculated by dividing the number of clusters (u) by the sum of the mean time that a cluster was attached to the teats (m.at.) and the mean time that the cluster was not in use (m.st) during the changeover from one cow to the other and while emptying the bucket (the latter only with method A). Hence the performance was $\frac{u}{\text { m.at. }+ \text { m.st. }}=\ldots \frac{\text { cows }}{\text { min }}$ and $\frac{\mathrm{u}}{\text { m.at. }+ \text { m.st. }} \times \mathrm{q}=\ldots \mathrm{kg} / \mathrm{min}$, in which $\mathrm{q}$ is the average milk yield per cow.

Consequently the milking performances in the cowshed and the milking parlour are not directly comparable. Moreover the milk yield was different in the two periods.

The mean heart rates of the subjects indicate a small to moderate physical effort, which agrees with the conclusion drawn from the energy expenditure.

The heart rates of the subjects remained steady, at least no certain increase could be shown. This indicates that milking by either method can be carried out for a longer continuous period.

The differences of the heart rates of the subjects between methods $A$ and $\mathbf{M}$ are small (only significant in the milking parlour). In the cowshed the difference found in three out of six subjects was even contrary to expectation. Subject EV showed the greatest difference between $\mathbf{M}$ and $\mathbf{A}$. This was caused by an unusually higher heart rate level on the days that EV milked with the ordinary buckets. EV did not have the same milking experience as the other subjects and this may have showed itself in the more complicated method A.

Both in the cowshed and the milking parlour the milking performance (cows/min) was greater with pipeline milking than with ordinary buckets. The time-saving was $18 \%$ in the cowshed and $9 \%$ in the milking parlour. It should be noted that more time is saved in the cowshed than in the parlour because more operations are performed in changing the units and greater distances are covered in emptying the buckets. Hence the work done in the cowshed could be simplified to a greater extent than that done in the milking parlour.

The performance level is low compared with the standards used for different milking methods in the Netherlands (Born and VRIEND, 1960; PostMa and VAN Elderen, 1963; Vos, 1960). The main cause of this low performance level is the small milking rate (TABLE 2). The milking rate was calculated by dividing the milk yield $q$ by the time that units were attached to the teats (m.at.), viz. $\frac{\mathrm{q}}{\mathrm{m} . \mathrm{at}} \mathrm{kg} / \mathrm{min}$.

TABLE 2. Some data on the experimental groups of cows

\begin{tabular}{|c|c|c|c|}
\hline & \multirow{2}{*}{$\begin{array}{l}\text { Cowshed } \\
\text { afternoon }\end{array}$} & \multicolumn{2}{|c|}{ Milking parlour } \\
\hline & & morning & afternoon \\
\hline Average milk yield $\mathrm{kg} / \mathrm{cow}$ & 3.5 & 7.5 & 6.0 \\
\hline Average milking rate $\mathrm{kg} / \mathrm{min}$ & 0.8 & 1.2 & 1.0 \\
\hline
\end{tabular}

It was assumed that in a detailed study of the heart rate the specific differences between both methods could be shown. 
FIG. 2. The average heart rate during each operation, and average time spent on machine milking with ordinary buckets (A) and milk pipeline (M); milker AV

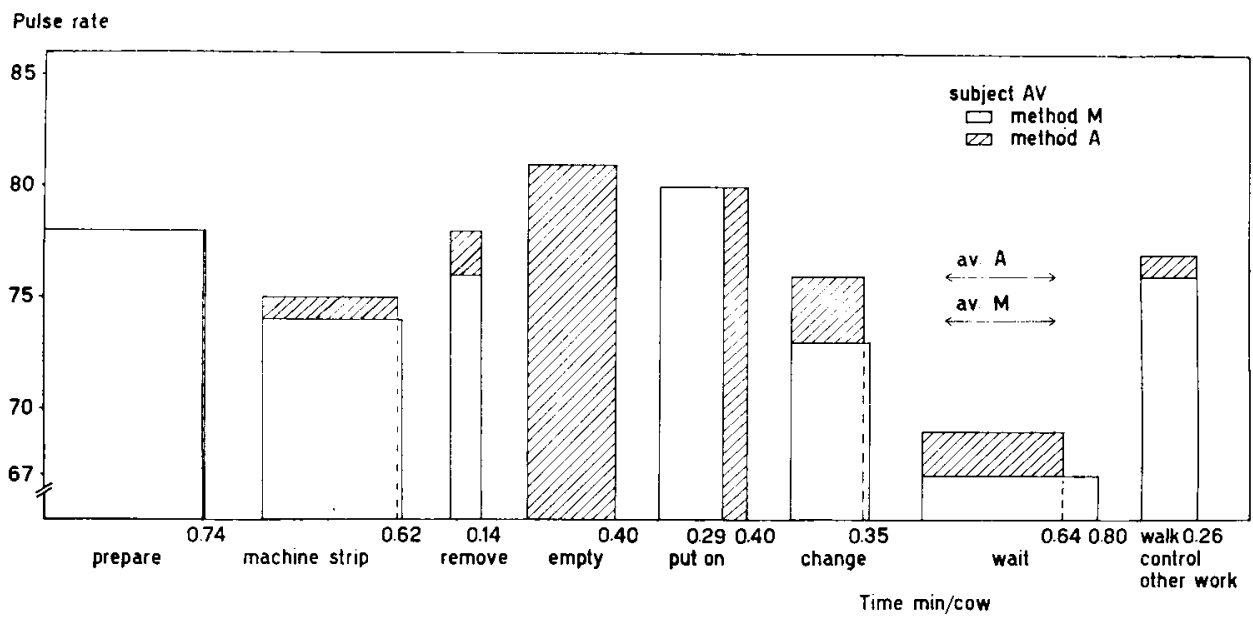

TABLE 3 and FIG. 2 show the mean heart rate, calculated for different operations, and the mean time per operation and their fraction of the total milking time (only for the three subjects and subject AV resp. in the milking parlour). A remarkable feature is the close agreement in the heart rate between operations not affected by either method of milking, e.g. the preparation and machine stripping of the cows.

The average heart rate during emptying of the buckets was not greater than during preparation of the cows, but the total time is increased by this operation, while the waiting time is reduced. Hence the different ratios between the active and inactive time of the milker is probably the main cause of the slight difference in the average effort between both milking methods,

It was also thought that the possible increase in the heart rate was noticeable during the operations following the emptying of the buckets. These operations were the attaching of the teat-cups and the changing of the cows, the latter operation being performed when the milk was not poured out into the milkcans direct but first into another bucket. In these operations subjects $\mathrm{AV}$ and $\mathrm{CV}$ showed a slightly greater heart rate in method $\mathrm{A}$. On the other hand, the heart rate during these operations is exactly the same as that during preparation.

Even if we select the emptying of full buckets, the total weight carried in one hand being $16 \mathrm{~kg}$ (weight of bucket $4 \mathrm{~kg}$, weight of milk $12 \mathrm{~kg}$ ), no marked increase in the heart rate was found as compared with the preparation of the cow.

Naturally the heart rate of subjects AV and DV decreased during waiting. Subject CV did not show the same decrease, but on the other hand his waiting time was much shorter.

Another interesting point is the heart rate of DV during machine stripping, which was greater than during preparation, unlike the heart rate of subject AV whose heartrate levels were reversed. But subject DV employed a much more intensive udder massage than AV, which might well explain this difference.

The carrying distance and time in the cowshed was longer, but the weight carried 


\section{EFFORT AND TIME IN PIPELINE MILKING}

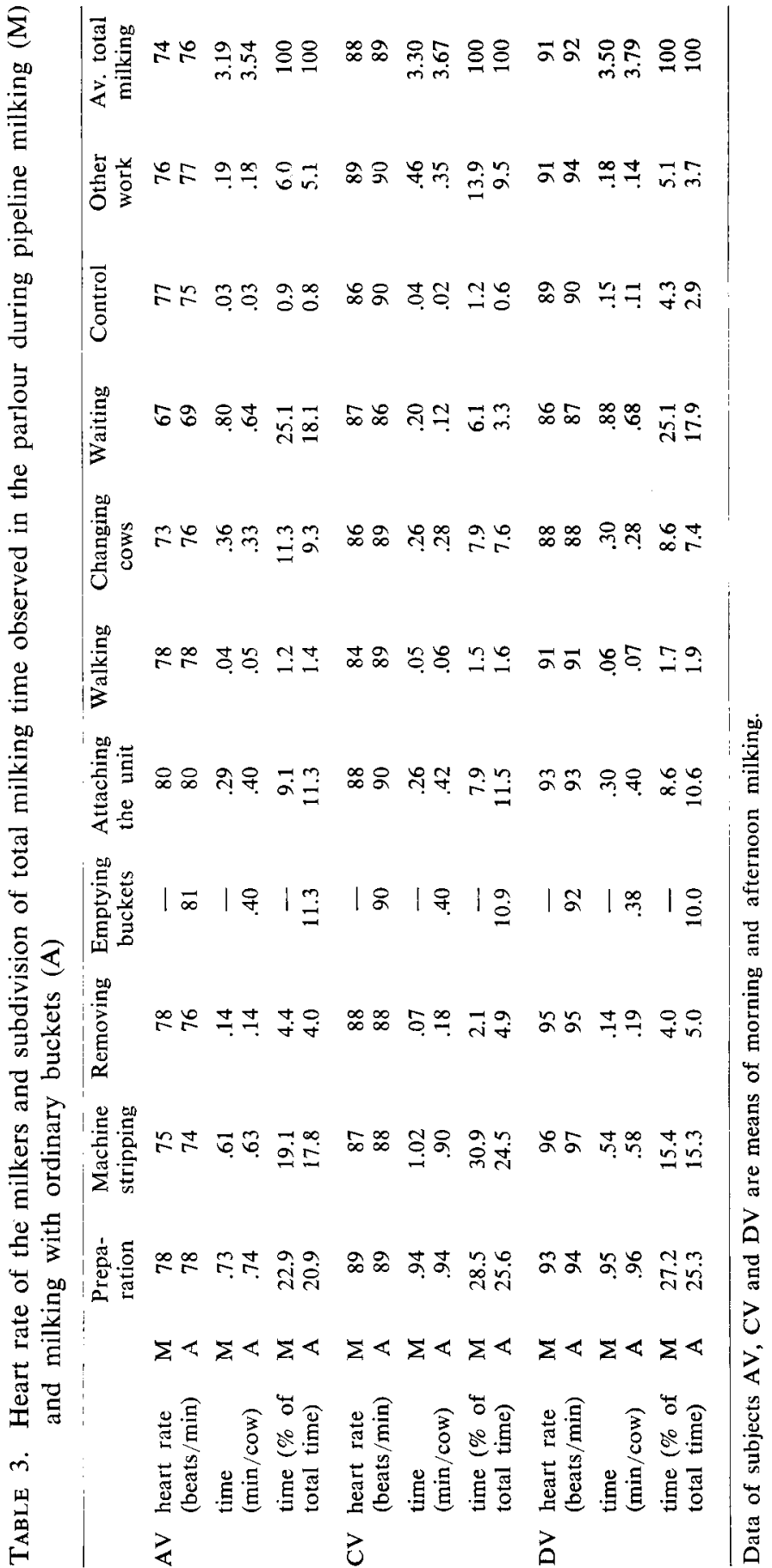

Neth. J. agric. Sci., Vol. 14 (1966) No. 1 (February) 
was smaller (average $7,5 \mathrm{~kg}$ ) during transport and emptying of the buckets. The effort expended during carrying of the buckets was intermediate between that of the preparation and machine stripping of the cows, so that it hardly affected the average physical effort.

In method A the filled 30-litre containers were carried and the utensils cleaned. TABLE 4 shows the heart rate and the percentage division of the time. The milking time has been corrected for 10 cows.

TABLE 4. Milking with ordinary buckets; heart rates compared for milking, carrying filled milkcans and cleaning utensils by hand, and the time percentage taken for each task

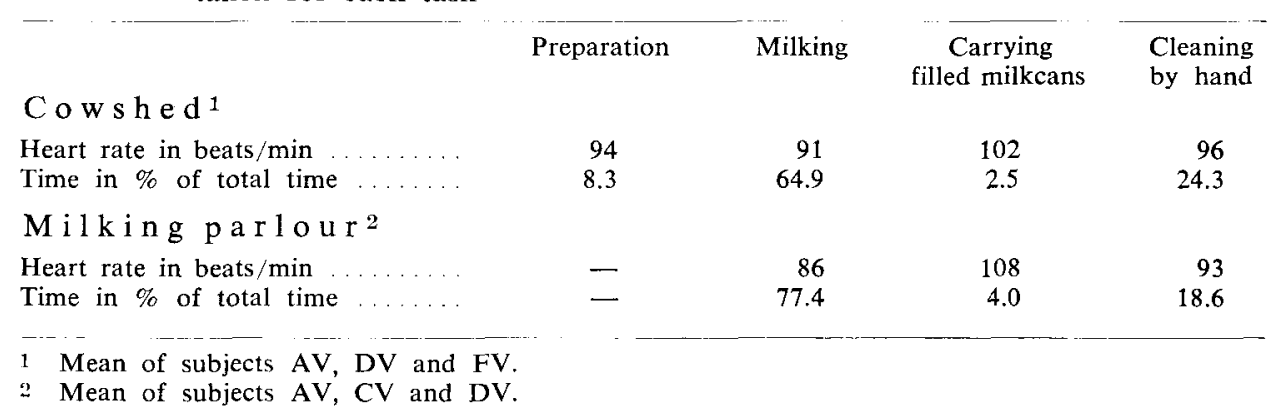

It is clear that a greater effort is required for carrying the milkcans, despite the fact that it took less time. More effort is needed for cleaning than for milking. It should be added that a stooping posture was maintained during cleaning.

The automatic cleaning of the pipeline and clusters in method $\mathbf{M}$, including the cleaning by hand of the other utensils (wash bucket, foremilk cup, towel, lids and pipe connections) took the same time as cleaning by hand in method $\mathrm{A}$. In this investigation the time was approximately $13.5 \mathrm{~min}$ per two units in the cowshed and approximately $9 \mathrm{~min}$ per two units in the milking parlour.

The effort expended on cleaning seemed to be somewhat less in method $M$. In the cowshed the heart rate was 93 beats $/ \mathrm{min}$ in method $M$ (average of subjects AV, DV and FV) or 3 beats/min less than in method A, which was 96 beats/min (TABLE 4 ).

\section{Discussion}

From the point of view of human labour machine milking is advantageous. Especially favourable elements are the great variation of the operations, the short duration of each operation and the regular short resting periods while waiting. As we have seen, the introduction of a milk pipeline has little or no effect on the workload. However it may be said that the pipeline simplifies the pattern of work and this results in a saving of time.

The experimental set-up was not unfavourable for the method in which ordinary buckets were used. The milk weight carried was 1 to $2 \mathrm{~kg} / \mathrm{min}$ (TABLE 1) and this quantity could easily be increased to $3 \mathrm{~kg} / \mathrm{min}$ at higher work performances or a higher milk yield of the cows. The rate of emptying a bucket would then also be increased, but in this case it does not seem likely that carrying and emptying of the buckets would actually cause peak loads. At a higher milking performance the activities would 
increase at the cost of the waiting time, so that the average effort would also increase. The level of the heart rate during preparation of the cow would probably be the upper limit, the latter operation taking up most of the milking time.

It was stated in the introduction that pipeline milking allows a better control of the work because more time is available. Of course this advantage applies when, as in our experiment, no other alterations are introduced. But if the time saved by pipeline milking is used to increase the output, e.g. by increasing the number of milk units used simultaneously, this gain in quality would again be lost.

Close supervision by the milker is necessary to establish the moment at which

1. the preparation of the cow should start;

2. the teat-cups should be applied;

3. the teat-cups should be removed.

The stricter the milking-technique standards, the greater should be the accuracy with which the correct moment for these operations is established. (In the Netherlands much value is attached to high-grade milking techniques).

High performances, which can be attained with more than one or two milking units per milker, mean an increase in the number of controls per minute. This might have the effect of increasing the mental strain placed on the milker (PosTMA, 1963).

Some suggestions for reducing mental effort could be given, e.g.

1. In order to faciliate a rapid and accurate visual control a good view of the control points is necessary. It might therefore be important to have a good general illumination in the parlour and perhaps a spot-light on the udder, teat-cups and other control points.

2. The period between attaching and removing the teat-cups is practically constant for the same cow. Generally speaking the milker knows whether a unit is required for a long or short period. A watch on the wall with a clear minute indication might be useful for fixing the moment at which the teat-cups can be removed. A watch would make it easier to prevent removal of two or more units together. In this way one of the bottlenecks could be eliminated.

3. The work could be organized in two different ways, namely the 'one unit-one stall' system and the 'one unit-two stall' system (Anon, 1959; STURrock and BraySHAW, 1958).

The 'one unit-one stall' system requires the simplest organization; preparation and attaching of the unit are in direct succession without changing from one cow to the other. Moreover the unit is always available when the preparation starts.

These two points have a great advantage over the 'one unit-two stall' system, in which after preparing one cow the milker changes to the next for machine stripping and removal of the clusters and changes again to the first cow to fit the teat-cups, possibly too late for milk ejection in the udder.

The 'one unit-one stall' system might also be employed in a herringbone parlour with 4 units and 8 stalls or 5 units and 10 stalls in which the 'one unit-two stall' system is usually practised. In such a parlour the performance could be $36-46$ cows an hour (Anon, 1959; Vos, 1960). A slightly modified 'one unit-one stall' system could be carried out as follows in this special kind of parlour: - 
operation 1 (left-hand stalls): Five cows are admitted and fed.

operation 2 (left-hand stalls): The cows are prepared and clusters are applied in succession (first the cows with the lowest milking rate or longest machine time on the cow).

operation 3 (right-hand stalls): Five cows are admitted and fed.

operation 4 (left-hand stalls): The cows are machine stripped and the units removed in succession.

operation 5 (right-hand stalls): as for operation 2 .

operation 6 (left-hand stalls): as for operation 3, etc.

Operation 2 can be modified in different ways, e.g. the five cows are first prepared and the clusters applied later on, or three cows are prepared and three clusters applied, after which the other two cows are prepared and the remaining clusters attached. The milker should always ensure that the five cows are ready at nearly the same moment and that the waiting times are short between preparation and attachment.

In this way there are only five simultaneous controls, viz. the 5 cows at the side to which the units are attached. Another considerable advantage is that the milker starts work again with each group of five cows and never has to get up to attend to operating units on the other side of the parlour. The milker needs $7.5 \mathrm{~min}$ for 5 cows. The units could operate from $2-7$ minutes, which is variable enough to enable individual care to be given to each cow. Cows have 7 minutes to eat the feedstuffs. Of course, there should be pipeline milking in this type of parlour in order to minimize the routine time. Feeding should be automatic.

\section{ACKNOWLEDGEMENTS}

The author is grateful to Prof. Dr. Th. Stegenga of the Agricultural University for the hospitality given in his department, to Mr. M. Keuls for advice on mathematics, to Mr. J. VAN SLOoten for technical assistance, and to the milkers for volunteering as subjects.

Anon

BoRn, F. H., and

J. I. M. VRIEND

Christensen, E. H.

Hettinger, Th., and W. WIRTHS

MülLER, E. A., and H. Franz

Politiek, R. D., and J. DE ROOY

Postma, G. and E. VAN ELDEREN

\section{REFERENCES}

1959 Machine milking. Min. of Agric. Fish. \& Food, London. Bull. No. 177.

1960 Machinaal melken in binnen- en buitenland. (Machine milking in the Netherlands and abroad). Meded. No. 37, Landb.Econ. Inst., Den Haag.

1953 Physical valuation of work in Nykroppa iron works. Symp. on Fatigue, The Ergonomics Res. Soc.

1953 Über die körperliche Beanspruchung beim Hand- und Maschinenmelken. Arbeitsphysiol. 15, 103-110.

1952 Energieverbrauchmessungen bei beruflicher Arbeit mit einer verbesserten Respirationsgasuhr. Arbeitsphysiol. 14, 499-504.

1962 Namelken met de hand of met de melkmachine. (Stripping with hand or milking machine). Inst. Veeteeltk. Onderz. 'Schoonoord', Zeist. Rep. No. B 38.

1963 Arbeidsfysiologie en arbeidspsychologie bij diverse methoden van melken. (Physiology and psychology of labour with different milking methods). Landb. mech. 14, 73-82.

1963 Arbeidsbegroting met behulp van taaktijden. (Labour planning with the aid of standard times). Inst. Landb. techn. Ration. Wageningen. Rep. No. 70. 
Roberts, W. P.

Streef, G. M., J. H. van LoON and H. W. Vos

STurrock, F. G., and G. H. BrayshaW

Vos, H. W.

WEIR, J. B. DE
1961 Selecting a milking parlour for the individual farm. Ergonomics. 4, 83 (abstr.).

1959 Arbeidsfysiologisch onderzoek in de landbouw. (Physiological research of labour in agriculture). Inst. Landb. techn. Ration. Wageningen. Rep. No. 8.

1958 Planning the farm to save labour. Univ. Cambridge, Farm ec. branch. Rep. No. 47.

1960 De arbeid bij de rundveeverzorging. (Chore labour in dairy farms). Inst. Landb. techn. Ration. Wageningen. Rep. No. 56.

1949 New methods for calculating metabolic rate with special reference to protein metabolism. J. Physiol. 109, 1-9. 